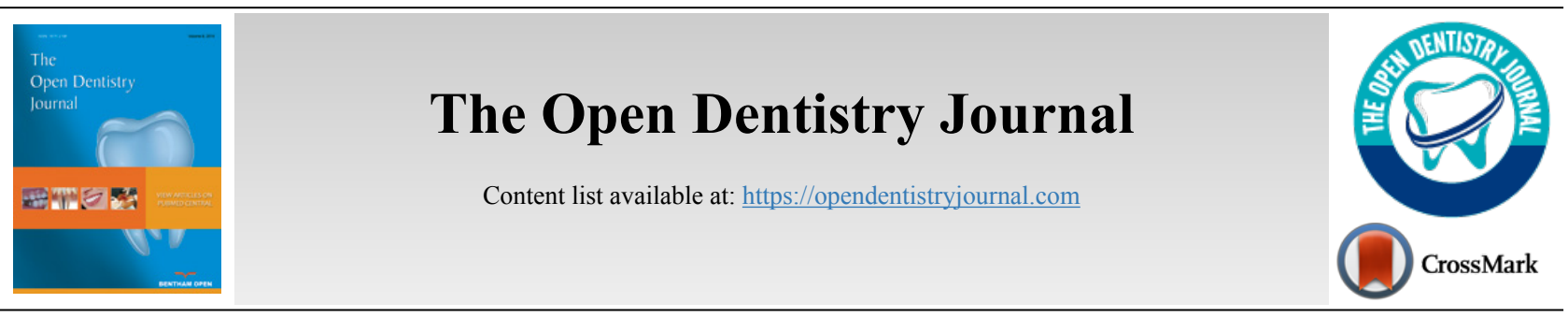

RESEARCH ARTICLE

\title{
COVID-19 and Infection Control in Dental Clinics; Assessment of Public Knowledge, Attitudes and Practices in Several Regions of Saudi Arabia
}

\author{
Mona Rajeh ${ }^{1, *}$ \\ ${ }^{I}$ Department of Dental Public Health and Community Dentistry, Faculty of Dentistry, Umm Al-Qura University, Makkah, Saudi Arabia
}

\begin{abstract}
:
Background:

The recent outbreak of the Corona Virus Disease (COVID-19) has affected millions of lives in different countries including the Kingdom of Saudi Arabia. Due to the characteristics of dental practice settings, there is a high risk of infection transmission between patients and dentists.

\section{Objectives:}

The aim of this study was to assess the level of public knowledge, attitude and practice regarding COVID-19 and infection control when visiting a dentist.

\section{Methods:}

In April 2020, a web-based cross-sectional survey was distributed randomly among the public through social media platforms. A validated anonymous questionnaire was used to assess knowledge about COVID-19 and participants' attitudes toward extra measures to prevent the spread of infection.

Results:

Among the completed questionnaires $(\mathrm{N}=521)$, the mean age of the participants was 36.24 years, $68.3 \%$ were women, $87.5 \%$ held a university degree, and $81 \%$ were from the Makkah region. Most of the participants (99\%) obtained a good knowledge score regarding COVID-19. Women were more likely than men to have more knowledge $(\mathrm{p}<0.05)$. Nearly all of the participants $(99.6 \%)$ demonstrated good attitudes towards precautionary measures in dental clinics.

Spearman's rho test showed a statistically significant correlation between age and attitude score, suggesting that attitude score increased with age $(\mathrm{p}<0.05)$. Overall, $73.3 \%$ reported that they would maintain good hygiene practices when visiting a dentist during this pandemic.

Conclusion:

Most Saudi residents with a high education level are knowledgeable about COVID-19, hold promising attitudes, and have appropriate practices towards precautionary measures needed while visiting a dental clinic during the virus outbreak.
\end{abstract}

Keywords: Knowledge, Attitude, Practice, COVID-19, Dentistry, Infection control.

\begin{tabular}{|l|l|l|l|}
\hline Article History & Received: May 22, 2020 & Revised: August 2, 2020 & Accepted: August 6, 2020
\end{tabular}

\section{INTRODUCTION}

In January 2020, the Chinese Center for Disease Control and Prevention announced the emergence of a novel coronavirus (COVID-19) in Wuhan, China [1]. The resulting COVID-19 pandemic has become a global public health crisis, with 15,296, 926 cases and 628,903 deaths worldwide [2]. As

\footnotetext{
* Address correspondence to this author at Department of Dental Public Health and Community Dentistry, Faculty of Dentistry, Umm Al-Qura University, Makkah, Saudi Arabia, Email: mtrajeh@uqu.edu.sa
}

of 24 July 2020, the Kingdom of Saudi Arabia reported the second largest number of cases in the Eastern Mediterranean region, where over 260,394 cases were reported, with a recovery rate of $81.9 \%$ and around $1 \%$ mortality rate $[2,3]$.

COVID-19 is an acute respiratory syndrome which can cause fever, dry cough, shortness of breath, fatigue, and other atypical symptoms such as muscle pain and headache [4]. It spreads more rapidly than the Severe Acute Respiratory Syndrome (SARS), and the rates of human-to-human trans- 
mission were generally higher when compared with the Middle East Respiratory Syndrome (MERS) [5]. Researchers suggest that transmission occurs between individuals via airborne droplets and contact with an infected person or contaminated surface $[5,6]$.

Given the nature of dental practice, there is a high risk of infection transmission between patients and dental practitioners due to the formation of a large number of droplets and aerosols during treatment [7]. The standard protective measures in daily clinical work are not sufficient to prevent the spread of COVID-19, therefore, strict and urgent infection control protocols are needed [7]. For example, the World Health Organization (WHO) recommends that dental clinics institute routine pre-appointment triaging, temperature measurement, detailed health status investigation, and checking of COVID-19 risk factors including recent travel and contact with an infected person [8]. Elective dental treatments should be deferred for at least 2-3 weeks for patients who present with fever and/or respiratory symptoms. However, when dental treatment is needed, dentists are required to follow more strict guidelines on infection prevention and control when dealing with suspected or confirmed cases of COVID-19. It is currently recommended that dentists use disposable hand instruments, frequently disinfect surfaces with chemicals approved for COVID-19, and minimize or avoid procedures that produce droplets [7]. Moreover, they should wear protective equipment including face shields, gowns, and N95 masks [7]. A previous study has issued specific guidelines and recommendations to deal with infectious diseases, such as the use of low or high volume saliva ejectors, which can reduce the production of droplets and aerosols [9]. With the increasing demand for dental care among individuals, patients should be aware of extra precautions to minimize the spread of infection. Patients should wear a surgical mask, cover their mouth and nose, and perform frequent hand hygiene [10].

As there is no current treatment, prevention and increasing awareness of extra precautions during this pandemic outbreak of COVID-19 are essential for protecting people. Efforts have been undertaken by the Saudi government through massive media campaigns to increase the level of awareness of the disease and public adherence to preventive measures to control the spread of the disease. Hence, it is expected that the Saudi population gained awareness and knowledge about the disease and its mode of prevention and transmission.

Most of the available studies into knowledge of infection control have investigated dentists and dental students, rather than patients $[11,12]$. Therefore, to address this knowledge gap, this study aimed to assess the level of Knowledge, Attitude and Practice (KAP) of the public about COVID-19 and extra precautions needed when attending dental clinics during the outbreak in Saudi Arabia.

\section{MATERIALS AND METHODS}

\subsection{Study Design}

During April 2020, we conducted a descriptive crosssectional survey among adult individuals in different regions of Saudi Arabia. We included individuals who fit the age group (over 18 years old), men or women, of any educational level. We excluded healthcare staff or students, and anyone who refused to participate. The sample size was calculated using OpenEpi online sample size calculator, using an estimated prevalence of $50 \%$, a precision level of $5 \%$, and a confidence interval of $90 \%$, we identified that the minimum number of participants needed for this study was 271 . The study was approved by the Faculty of Dentistry Institutional Review Board, Umm Al-Qura University (IRB number 172-2020).

An online survey was created using SurveyMonkey and sent randomly to the public through social media platforms. Due to current official restrictions, the questionnaire was promoted mainly via Facebook, WhatsApp, and Twitter messages by the author, with recipients being asked to share the survey with their connections. All participants gave written informed consent, and participation was voluntary and anonymous. It took approximately 5 minutes to complete the questionnaire. The questionnaire was prepared in Arabic and English formats to correspond with the reading and comprehension levels of participants with different levels of education.

\subsection{Questionnaire}

A 20-item questionnaire was developed according to guidelines proposed by the Centers for Disease Control and Prevention (CDC) and WHO $[8,13]$. It was based on questionnaire used in a previous study [14], and was divided into four parts. The first part explored the sociodemographic characteristics of the participants. The second part assessed participants' knowledge regarding COVID-19. It consisted of 9 multiple-choice questions, for each of which a score of 1 was given for the correct answer and 0 for the incorrect or unknown answers. A total knowledge score was calculated, ranging from 0 to 9 . Knowledge was classified into three groups according to the total score of each respondent; poor (0-3), moderate (4-6), and high (7-9).

The third part measured participants' attitudes and opinions toward extra measures required to prevent COVID-19. This part consisted of 10 statements with which participants indicated their level of agreement using a 3-point Likert scale (a score of 1 being disagreement and 3 being agreement), giving each participant a total score of between 10 and 30 for this section. The fourth part included questions to gauge participants' practice of hypothetical situations, such as accepting dental treatment from a dentist who is not wearing a mask or gloves. It involved 10 yes/no questions. The minimum score was 0 , and the maximum was 1 , of which a score of 5 and less considered poor practice and score of 6 and more considered as good practice.

The explanatory (independent) variables were the participants' gender, nationality, region, level of education and working status. The dependent variables of interest were the questions related to the respondents' knowledge, attitude and practice.

Initially, we consulted two experts to ensure the content and face validity of the questionnaire, one from the Preventive Dentistry Department of Umm Al-Qura University, who had clear understanding of infection control and the COVID-19 guidelines for healthcare workers; and the other with an 
expertise in questionnaire development. They evaluated the items of the questionnaire for clarity, importance, and relevance. Based on the experts' feedback, minor changes were made in word choices and sentence structure. The developed questionnaire was then pilot tested on a convenient sample of 25 participants to evaluate the format and sequence of the questions. Participants were encouraged to share their thoughts about the items with the researcher and provide feedback about the content and clarity of the draft questionnaire. The questionnaire was then reviewed, and minor modifications were made (e.g., clarifying the questions). Test-retest reliability was determined where participants completed the questionnaire twice within a one-week interval and Cronbach's alpha was 0.78 .

\subsection{Statistical Analysis}

Data were analyzed using the Statistical Package for the Social Sciences (SPSS Version 22.0, Chicago, IL, USA). Descriptive analysis, including frequency (percent) and mean (standard deviation), was performed to present an overview of the findings. Fisher's exact test was conducted to determine the associations between knowledge and practice scores by demo- graphic. Mann-Whitney $U$ test was used to compare the attitude scores by demographic. Spearman correlation was used to determine the correlation between knowledge, attitude, and practice scores with age. All $\mathrm{p}$-values $\leq 0.05$ were considered statistically significant.

\section{RESULTS}

Of the total 521 participants, the majority were women $(68.3 \%, \mathrm{n}=356)$, Saudi nationals $(91.0 \%, \mathrm{n}=474)$, residents from Makkah region $(81.0 \%, \mathrm{n}=422)$, University level of education $(87.5 \%, \mathrm{n}=456)$, and employed $(57.6 \%, \mathrm{n}=300)$ (Table 1). The mean \pm SD age of the participants was $36.24 \pm$ 11.41 years, ranging from 18-83 years. Most of the participants reported correct responses to knowledge statements, as shown in Table 2. Notably, $46.8 \%(n=244)$ and $49.1 \%(n=256)$ reported that COVID-19 is dangerous, and very dangerous, respectively. Most of the participants reported the website of the Ministry of Health $(35.7 \%)$, followed by social media (27.6\%) and TV (19.5\%) as their preferred sources of information about COVID-19. Only $8.8 \%(n=46)$ reported that they had visited the dentist during the COVID-19 outbreak. Fig. (1) presents the reasons for visiting a dentist.

\section{Table 1. Demographics of the participants.}

\begin{tabular}{|c|c|c|c|}
\hline \multicolumn{2}{|c|}{-} & \multirow{2}{*}{$\begin{array}{l}\text { Mean } \\
36.24\end{array}$} & \multirow{2}{*}{\begin{tabular}{|c|} 
SD \\
11.41
\end{tabular}} \\
\hline Age & - & & \\
\hline & - & $n$ & $\%$ \\
\hline \multirow[t]{2}{*}{ Gender } & Male & 165 & 31.7 \\
\hline & Female & 356 & 68.3 \\
\hline \multirow[t]{2}{*}{ Nationality } & Saudi & 474 & 91.0 \\
\hline & Non-Saudi & 47 & 9.0 \\
\hline \multirow[t]{5}{*}{ Region } & Makkah & 422 & 81.0 \\
\hline & Riyadh & 56 & 10.7 \\
\hline & Madinah & 13 & 2.5 \\
\hline & Western region & 23 & 4.4 \\
\hline & Asir & 7 & 1.3 \\
\hline \multirow[t]{4}{*}{ Level of education } & Elementary & 3 & .6 \\
\hline & Intermediate & 9 & 1.7 \\
\hline & High school & 53 & 10.2 \\
\hline & University & 456 & 87.5 \\
\hline \multirow[t]{2}{*}{ Working status } & Working & 300 & 57.6 \\
\hline & Not working & 221 & 42.4 \\
\hline
\end{tabular}

Table 2. Knowledge of participants about COVID-19.

\begin{tabular}{|c|c|c|c|}
\hline \multicolumn{2}{|l|}{-} & $\mathbf{n}$ & $\%$ \\
\hline \multirow[t]{6}{*}{ What are the symptoms of corona virus COVID-19? } & Fever* & 507 & 23.2 \\
\hline & Cough* & 447 & 20.5 \\
\hline & Difficulty breathing* & 501 & 23.0 \\
\hline & Fatigue* & 349 & 16.0 \\
\hline & Headache* & 346 & 15.9 \\
\hline & Skin rash & 32 & 1.5 \\
\hline
\end{tabular}




\begin{tabular}{|c|c|c|c|}
\hline \multirow[t]{4}{*}{ Who are at higher risk of having COVID-19? } & Children & 164 & 15.0 \\
\hline & Elderly* & 459 & 41.9 \\
\hline & People with chronic disease* & 463 & 42.2 \\
\hline & I don't know & 10 & 0.9 \\
\hline The incubation period of COVID-19 is & 2-7 days & 11 & 2.1 \\
\hline- & 7-14 days* & 452 & 86.8 \\
\hline- & More than 14 days & 53 & 10.2 \\
\hline- & I don't know & 5 & 1.0 \\
\hline How is COVID-19 transmitted? & Direct contact & 18 & 3.5 \\
\hline- & Indirect contact & 26 & 5.0 \\
\hline- & Both* & 475 & 91.2 \\
\hline- & I don't know & 2 & .4 \\
\hline Do you think COVID-19 is: & Not dangerous & 21 & 4.0 \\
\hline- & Dangerous* & 244 & 46.8 \\
\hline- & Very dangerous & 256 & 49.1 \\
\hline $\begin{array}{l}\text { During COVID-19 outbreak, do you think dental clinics should measure your temperature before seeing the } \\
\text { dentist? }\end{array}$ & Yes* & 505 & 96.9 \\
\hline- & No & 16 & 3.1 \\
\hline $\begin{array}{l}\text { During COVID-19 outbreak, do you think dental clinics should ask you about your travelling trips during the } \\
\text { past } 14 \text { days? }\end{array}$ & Yes* & 496 & 95.2 \\
\hline- & No & 25 & 4.8 \\
\hline During visiting the dental clinic, do you think you should wash your hands frequently? & Yes* & 515 & 98.8 \\
\hline- & No & 6 & 1.2 \\
\hline During visiting the dentist, do you think you should rinse your mouth before starting dental treatment? & Yes* & 380 & 72.9 \\
\hline- & No & 141 & 27.1 \\
\hline
\end{tabular}

* Indicates correct answer

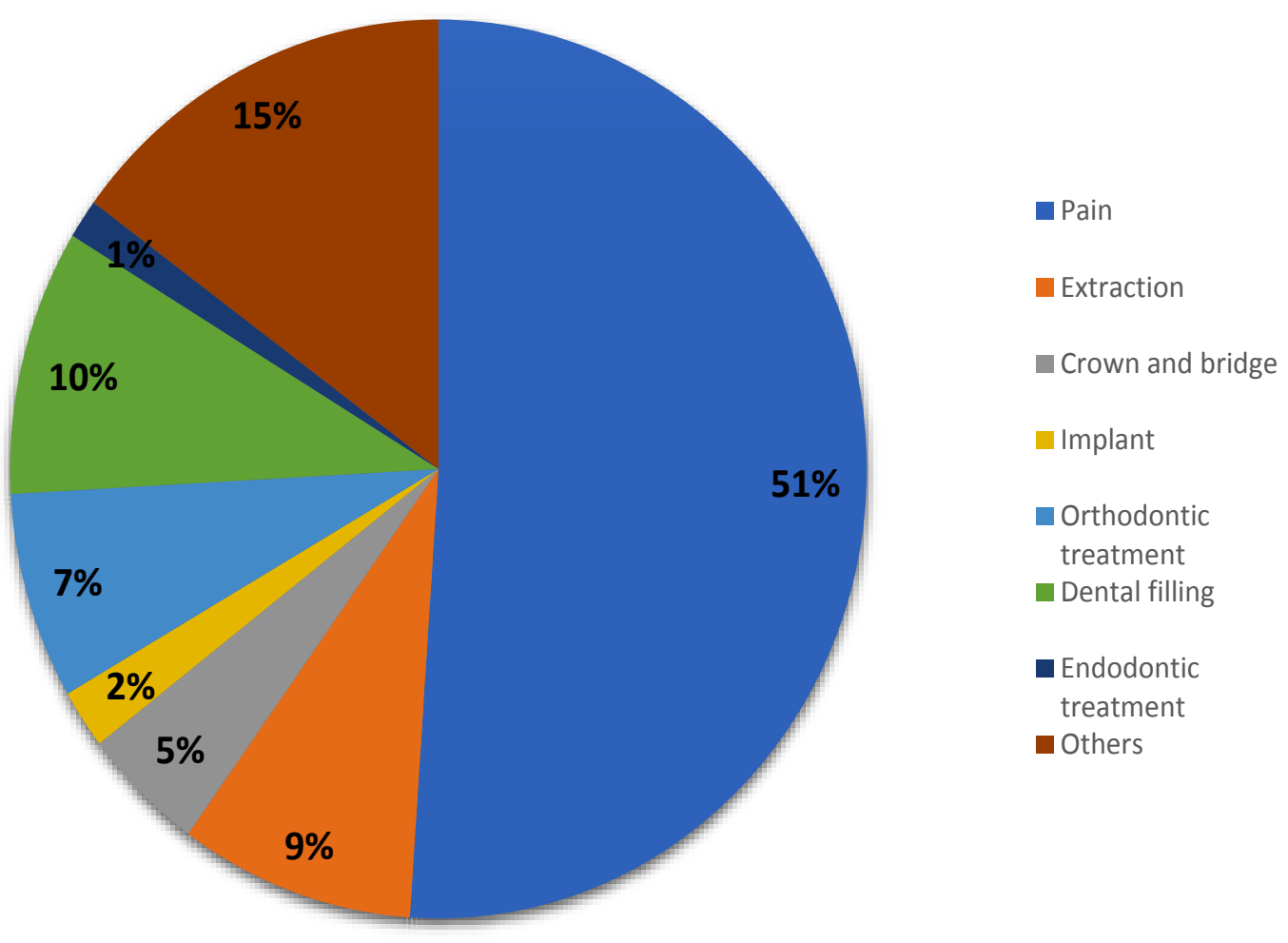

Fig. (1). Reasons for visiting a dentist during COVID-19 outbreak.

Most of the participants agreed with the statements on their visit to the dental clinic to minimize the spread of COVID-19. The majority disagreed that dentists can treat patients with the same gloves (Fig. 2). Most of the participants reported that they would observe good hygiene practices during a visit to the dentist during the COVID-19 outbreak (Fig. 3). 
The dentist should wear gloves while treating his patients

The dentist should change his gloves while answering his phone

*The dentist can treat patients with the same gloves

The dentist should wear mask while treating the patient

The dentist should wear goggles while treating the patient

Dental instruments should be regularly sterilized

The patient should wear mask while in the waiting area

The patient should wear gloves

The patient should wear goggles

The patient should wash his hands frequently

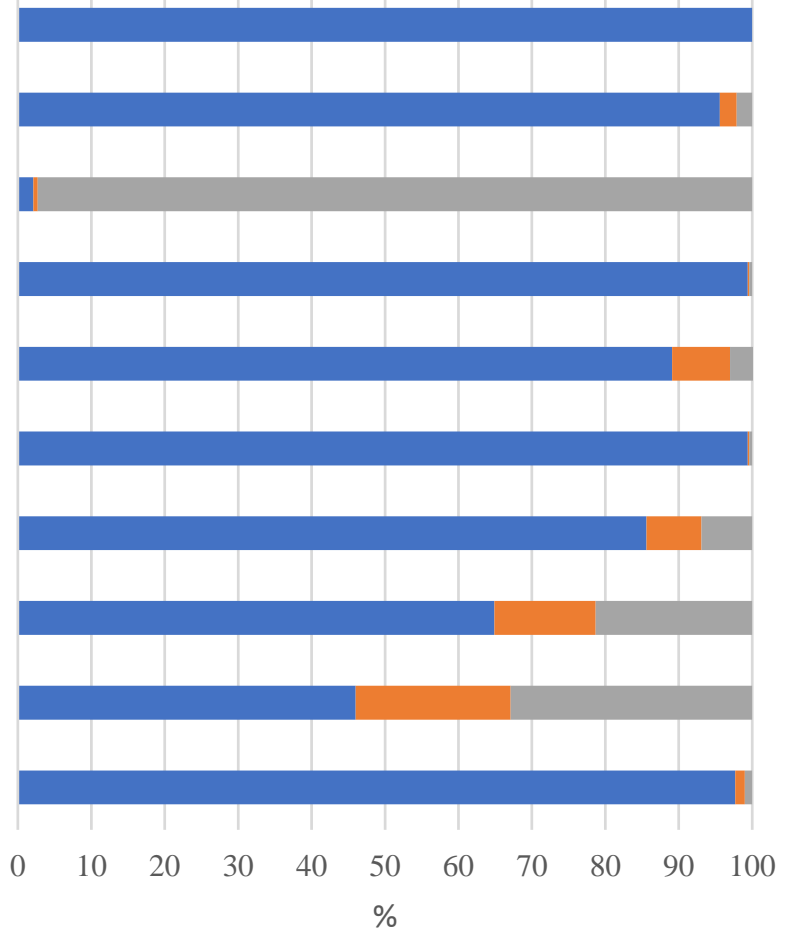

- Agree $\quad$ Neutral $\square$ Disagree

Fig. (2). Awareness of participants about covid-19 in a dental office.

Do you ask if the dental instruments are sterilized?

Do you ask how dental instruments are sterilized?

If your dentist is not wearing a mask, do you ask him to wear it?

If your dentist is not wearing goggles, do you ask him to wear them?

If your dentist is not wearing gloves, do you ask him to wear them?

If your dentist did not wash his hands before treating you, do you ask him to wash them?

If the dental clinic does not provide you with a mask, do you ask for one?

If the dental clinic does not provide you with gloves, do you ask for a pair?

If your dentist does not ask you to wash your hands before and after treatment, do you wash them?

If your dentist does not ask you to rinse your mouth, do you ask him to do so?

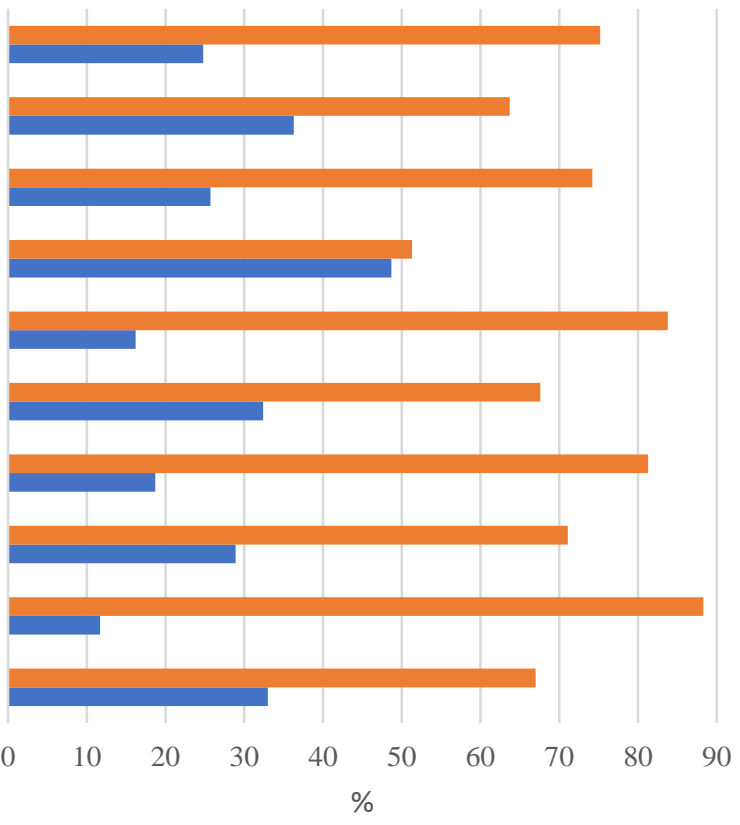

No $\square$ Yes

Fig. (3). Demand of participants regarding covid-19 in a dental office. 
Fisher's exact test showed that women were significantly more likely to have a high level of knowledge, and men were significantly more likely to have a moderate level of knowledge $(p<0.05)$. No statistically significant association was found between knowledge and nationality, region, level of education, or employment status ( $\mathrm{p}>0.05)$. None of the participants had a poor level of knowledge (Table 3). Spearman's rho test showed a negative correlation between age and knowledge level, suggesting that knowledge level decrea-sed with an increase in age. However, this relationship was not statistically significant $(\mathrm{p}>0.05)$.
The Mann-Whitney U test showed no statistically significant difference in the mean \pm SD attitude score by demographics $(\mathrm{p}>0.05)$ (Table 4). Spearman's rho test showed a statistically significant positive correlation between age and attitude score, suggesting that attitude score increased with age $(p<0.05)$. Fisher's exact test showed no statistically significant association between practice score and demographics $(\mathrm{p}>0.05)$ (Table 5). Spearman's rho test showed a positive correlation between age and practice, suggesting that practice score increased with age. However, this relationship was not statistically significant $(\mathrm{p}>0.05)$.

Table 3. Association between knowledge level and demographics.

\begin{tabular}{|c|c|c|c|c|c|}
\hline \multicolumn{2}{|c|}{ - } & \multirow{2}{*}{$\begin{array}{c}\text { Poor } \\
(0-3)\end{array}$} & \multirow{2}{*}{$\begin{array}{c}\begin{array}{c}\text { Moderate } \\
(4-6)\end{array} \\
n(\%)\end{array}$} & High & \multirow[t]{2}{*}{ p value } \\
\hline & & & & n (\%) & \\
\hline \multirow[t]{2}{*}{ Gender } & Male & $0(0.0)$ & $21(12.7)$ & $144(87.3)$ & \multirow[t]{2}{*}{0.029} \\
\hline & Female & $0(0.0)$ & $24(6.7)$ & $332(93.3)$ & \\
\hline \multirow[t]{2}{*}{ Nationality } & Saudi & $0(0.0)$ & $44(9.3)$ & $430(90.7)$ & \multirow[t]{2}{*}{0.107} \\
\hline & Non-Saudi & $0(0.0)$ & $1(2.1)$ & $46(97.9)$ & \\
\hline \multirow[t]{2}{*}{ Region } & Makkah & $0(0.0)$ & $41(9.7)$ & $381(90.3)$ & \multirow[t]{2}{*}{0.075} \\
\hline & Others & $0(0.0)$ & $4(4.0)$ & $95(96.0)$ & \\
\hline \multirow[t]{2}{*}{ Level of education } & Below University & $0(0.0)$ & $8(12.3)$ & $57(87.7)$ & \multirow[t]{2}{*}{0.244} \\
\hline & University & $0(0.0)$ & $37(8.1)$ & 419 (91.9) & \\
\hline \multirow[t]{2}{*}{ Working status } & Working & $0(0.0)$ & $26(8.7)$ & $274(91.3)$ & \multirow[t]{2}{*}{1.000} \\
\hline & Not working & $0(0.0)$ & $19(8.6)$ & $202(91.4)$ & \\
\hline
\end{tabular}

Fisher's exact test for statistical significance at $\mathrm{p} \leq 0.05$

Table 4. Comparison of mean attitude score based on demographics.

\begin{tabular}{|c|c|c|c|c|}
\hline \multicolumn{2}{|c|}{-} & Mean & Standard Deviation & p value \\
\hline \multirow{2}{*}{ Gender } & Male & 27.8 & 2.3 & 0.173 \\
\cline { 2 - 5 } & Female & 28.1 & 1.9 & 0.988 \\
\hline \multirow{2}{*}{ Nationality } & Saudi & 28.0 & 2.1 & 0.918 \\
\cline { 2 - 5 } & Non-Saudi & 28.0 & 2.0 & \\
\hline \multirow{2}{*}{ Region } & Makkah & 28.0 & 2.1 & 0.265 \\
\cline { 2 - 5 } & Others & 28.0 & 2.1 & 2.2 \\
\cline { 2 - 5 } & Below University & 28.2 & 2.0 & 0.463 \\
\cline { 2 - 5 } & University & 27.9 & 2.2 & 1.92 \\
\hline
\end{tabular}

Mann-Whitney $U$ test for statistical significance at $\mathrm{p} \leq 0.05$; Minimum score $=10$; Maximum score $=30$

Table 5. Association between category of practice and demographics.

\begin{tabular}{|c|c|c|c|c|}
\hline \multicolumn{2}{|c|}{ - } & \multirow{2}{*}{$\begin{array}{c}\text { Poor } \\
(0-5) \\
\text { n (\%) }\end{array}$} & \multirow{2}{*}{$\begin{array}{c}\begin{array}{c}\text { Good } \\
(6-10)\end{array} \\
\text { n (\%) }\end{array}$} & \multirow[t]{2}{*}{ p valuem } \\
\hline & & & & \\
\hline \multirow[t]{2}{*}{ Gender } & Male & $43(26.1)$ & $122(73.9)$ & \multirow[t]{2}{*}{0.915} \\
\hline & Female & $96(27.0)$ & $260(73.0)$ & \\
\hline \multirow[t]{2}{*}{ Nationality } & Saudi & $130(27.4)$ & $344(72.6)$ & \multirow[t]{2}{*}{0.299} \\
\hline & Non-Saudi & $9(19.1)$ & $38(80.9)$ & \\
\hline \multirow[t]{2}{*}{ Region } & Makkah & $111(26.3)$ & $311(73.7)$ & \multirow[t]{2}{*}{0.706} \\
\hline & Others & $28(28.3)$ & $71(71.7)$ & \\
\hline
\end{tabular}


(Table 5) contd.....

\begin{tabular}{|c|c|c|c|c|}
\hline \multicolumn{2}{|c|}{ - } & $\begin{array}{l}\text { Poor } \\
(0-5)\end{array}$ & $\begin{array}{l}\text { Good } \\
(6-10)\end{array}$ & p valuem \\
\hline \multirow[t]{2}{*}{ Level of education } & Below University & $11(16.9)$ & $54(83.1)$ & \multirow[t]{2}{*}{0.071} \\
\hline & University & $128(28.1)$ & $328(71.9)$ & \\
\hline \multirow[t]{2}{*}{ Working status } & I work & $81(27.0)$ & $219(73.0)$ & \multirow[t]{2}{*}{0.920} \\
\hline & I don't work & $58(26.2)$ & $163(73.8)$ & \\
\hline
\end{tabular}

Fisher's exact test for statistical significance at $\mathrm{p} \leq 0.05$

\section{DISCUSSION}

Based on the WHO guidelines, as a routine procedure, dental clinics are required to establish a precheck triage to measure the temperature of patients and obtain their travel history in the past two weeks [8]. Dental quality control centers in different cities implemented supplementary measures into their recommendations for dental services to ensure the quality of infection control [7].

In this study, we investigated 521 Saudi residents from different regions of Saudi Arabia and the majority of the respondents were from the Makkah region. This study included participants who had access to the internet. Hence, most of the participants had a higher level of education. To the best of our knowledge, no previous study was conducted on the population residing in Saudi Arabia to assess the KAP about extra precautions required when visiting dental clinics during the COVID-19 outbreak in Saudi Arabia.

Our results indicate that $91.4 \%$ of the participants had a high level of knowledge regarding the mode of spread, signs, and symptoms of COVID-19. This finding is in agreement with other studies that showed that the Saudi population was knowledgeable about previous epidemic diseases like MERS [15]. This might be due to the characteristics of our study sample, where $87.5 \%$ had university degrees. A study investigating Chinese citizens during the period of the COVID-19 outbreak, reported that $90 \%$ of their respondents were knowledgeable about COVID-19 [16]. In the United States, approximately eight weeks after the first case was diagnosed, the average knowledge score for US residents was 9.72 out of 12 (approximately 80\%) [17]. The high knowledge levels found in these studies might be due to the time when the questionnaires were distributed. During that period, people may have gained awareness about the disease from television and media to protect themselves and their families from contracting the disease. The majority of our participants gained knowledge about the disease from the Ministry of Health website, followed by social media and television.

It is worth mentioning that the massive ongoing awareness campaign raised by the Saudi Ministry of Health through their website and social media to fight the novel coronavirus might have contributed to a high level of knowledge among Saudi citizens and residents. The Ministry of Health issued a guide to COVID-19 in different languages about preventive measures to minimize the spread of the disease. These efforts made by the Saudi government to early engage the public with preventive and control measures affected their knowledge.

In this study, gender was significantly associated with knowledge level, with women obtaining a higher knowledge score than men. This finding is supported by other studies that have found that female and highly educated respondents are more knowledgeable about emerging infectious diseases [15, 18]. Additionally, this could be related to the fact that women are more likely to seek health information and be more curious about their own health than men $[19,20]$.

Attitudes to precautions to prevent COVID-19 in dental clinics were promising. The majority $(99.6 \%)$ agreed that the dentist and patient should wear personal protective equipment, such as masks. They also agreed that frequently disinfecting the dental surfaces, along with frequent hand hygiene, will reduce the risk of infection. These preventive attitudes could be attributed to the strict prevention and control measures issued by the Ministry of Health. The measures included closure of schools and universities, suspension of all flights, and obligatory wearing masks in public places and keeping social distance. The positive attitude of the participants could be a result of the good public knowledge about the infectivity of the COVID-19 virus. In line with findings from previous studies, Saudi dental patients have positive attitudes towards dentists using barrier methods to prevent infection during dental treatment [14, 21]. Moreover, the findings revealed that a high attitude score was more common among older people. This may be because older adults are at higher risk of severe illness from COVID-19. The awareness-raising efforts by the Ministry of Health and the strict precautionary measures announced by the Saudi government have likely helped to increase a sense of responsibility and societal awareness.

With regards to self-reported practices, our findings revealed that most of the participants $(73.3 \%)$ would act appropriately on their visit to the dentist during the COVID-19 outbreak. During this global crisis, the participants of the current study reported that they were more likely to refuse to receive dental treatment from a dentist who is not wearing personal protective equipment. Our result is consistent with previous studies in Saudi Arabia where the participants were aware of the importance of dentists wearing barrier methods to prevent infection during treatment $[14,21]$. According to the WHO guidelines, dentists should take strict personal protection measures and avoid or minimize procedures that can produce droplets or aerosols [7, 8]. Only dental emergencies should be treated during this pandemic period, and routine dental procedures should be deferred [7]. That being said, only $8.8 \%$ of the respondents reported visiting the dental clinic during the COVID-19 outbreak, and the main reason for their visit was dental pain. The good level of knowledge of proper hygienic practices observed in our sample is re-assuring.

Due to the scarcity of available data, there is no comparable study assessing attitudes and practice among the public 
regarding COVID-19 in the dental clinic. Most of the recent studies investigated dentists or healthcare workers [22 - 24]. These studies showed that dentists have a high level of knowledge and appropriate attitudes toward treating patients with COVID-19 [22, 23]. Therefore, this study shed light on an area where limited information is available, and, to the best of our knowledge, it is the first study conducted to assess public awareness of COVID-19 while visiting dental clinics in Saudi Arabia. The aforementioned findings suggest that the ongoing intensive health-awareness campaigns by the local government and the Ministry of Health have been effective in encouraging the community to take appropriate actions to reduce the spread of COVID-19.

This study had several limitations that must be acknowledged. Firstly, the collected data were self-reported by the respondents through an online questionnaire. Self-reported data cannot be independently verified and may be prone to response bias, such as exaggerated or understated responses by individuals. Secondly, the poorly chosen distribution channels through social media can lead to biased data and limit the generalizability of the findings. Finally, most of the respondents were highly educated and from the Makkah region. Vulnerable people in Saudi Arabia, such as rural people with low educational levels, are more likely to have poor knowledge, negative attitudes, and inappropriate preventive practices. Further studies to assess KAP towards COVID-19 dental infection control among these individuals are recommended.

\section{CONCLUSION}

During the coronavirus pandemic, highly educated Saudi citizens demonstrated good knowledge and optimistic attitudes towards maintaining safe practices regarding minimizing the spread of COVID-19 in the dental setting. This suggests that the massive public health education programs guided by local government and the Ministry of Health are helpful.

\section{LIST OF ABBREVIATIONS}

$$
\begin{aligned}
& \text { WHO }=\text { World Health Organization } \\
& \text { KAP }=\text { Knowledge, Attitude, and Practice } \\
& \text { CDC }=\text { Centres for Disease Control and Prevention }
\end{aligned}
$$

\section{ETHICS APPROVAL AND CONSENT TO PARTI- CIPATE}

This study received approval from the Institutional Review Board of Umm Al-Qura University, Saudi Arabia, with ethical approval number 172-2020.

\section{HUMAN AND ANIMAL RIGHTS}

Not applicable.

\section{CONSENT FOR PUBLICATION}

All participants signed the consent before participating in the study.

\section{AVAILIBILITY OF DATA AND MATERIALS}

The data that support the findings of this study are with the corresponding author, [M. R] and can be made available upon reasonable request.

\section{FUNDING}

None.

\section{CONFLICT OF INTEREST}

The author declares no conflicts of interest, financial or otherwise.

\section{ACKNOWLEDGEMENTS}

The author would like to thank all the participants involved in this study for their cooperation.

\section{REFERENCES}

[1] Li ZY, Meng LY. The prevention and control of a new coronavirus infection in department of stomatology. Zhonghua Kou Qiang Yi Xue Za Zhi 2020; 55(0): E001.

[PMID: 32057210]

[2] Coronavirus diseases-19 (COVID-19) situation reports. Available from https://www.who.int/emergencies/diseases/novel-coronavirus -2019 /situation-reports

[3] COVID-19 daily updates, Saudi Center for Disease Control and Prevention. Available from: https://covid19.cdc.gov.sa/daily-updates

[4] Chen N, Zhou M, Dong X, et al. Epidemiological and clinical characteristics of 99 cases of 2019 novel coronavirus pneumonia in Wuhan, China: A descriptive study. Lancet 2020; 395(10223): 507-13. [http://dx.doi.org/10.1016/S0140-6736(20)30211-7] [PMID: 32007143]

[5] Peeri NC, Shrestha N, Rahman MS, et al. The SARS, MERS and novel coronavirus (COVID-19) epidemics, the newest and biggest global health threats: What lessons have we learned? Int J Epidemiol 2020; 49(3): 717-26.

[http://dx.doi.org/10.1093/ije/dyaa033] [PMID: 32086938]

[6] Special Expert Group for Control of the Epidemic of Novel Coronavirus Pneumonia of the Chinese Preventive Medicine Association. [An update on the epidemiological characteristics of novel coronavirus pneumonia (COVID-19)]. Zhonghua Liu Xing Bing Xue Za Zhi 2020; 41(2): 139-44. [PMID: 32057211]

[7] Meng L, Hua F, Bian Z. Coronavirus disease 2019 (COVID-19): emerging and future challenges for dental and oral medicine. J Dent Res 2020; 99(5): 481-7.

[http://dx.doi.org/10.1177/0022034520914246] [PMID: 32162995]

[8] World Health Organization. Clinical management of severe acute respiratory infection when novel coronavirus (2019-nCoV) infection is suspected: Interim guidance. . Available From: https://www. who.int/docs /default-source/coronaviruse/ clinical-management-ofnovel-cov.pdf

[9] Samaranayake LP, Peiris M. Severe acute respiratory syndrome and dentistry: A retrospective view. J Am Dent Assoc 2004; 135(9): 1292-302.

[http://dx.doi.org/10.14219/jada.archive.2004.0405] [PMID: 15493394]

[10] Ather A, Patel B, Ruparel NB, Diogenes A, Hargreaves KM. Coronavirus disease 19 (COVID-19): Implications for clinical dental care. J Endod 2020; 46(5): 584-95.

[http://dx.doi.org/10.1016/j.joen.2020.03.008] [PMID: 32273156]

[11] Al-Maweri SATB, Tarakji B, Shugaa-Addin B, Al-Shamiri HM, Alaizari NA, AlMasri O. Infection control: Knowledge and compliance among Saudi undergraduate dental students. GMS Hyg Infect Control 2015; 10(10): Doc10. [PMID: 26199855]

[12] Setia S, Gambhir R, Kapoor V, Jindal G, Garg S, Setia S. Attitudes and awareness regarding hepatitis $\mathrm{B}$ and hepatitis $\mathrm{C}$ amongst healthcare workers of a tertiary hospital in India. Ann Med Health Sci Res 2013; 3(4): 551-8.

[http://dx.doi.org/10.4103/2141-9248.122105] [PMID: 24380007]

[13] CDC centers for disease control and prevention: Coronavirus (COVID-19) 2020. Available from at: https://www.cdc.gov/coronavirus/2019-nCoV/ index.html

[14] Ibrahim NK, Alwafi HA, Sangoof SO, Turkistani AK, Alattas BM. 
Cross-infection and infection control in dentistry: Knowledge, attitude and practice of patients attended dental clinics in King Abdulaziz University Hospital, Jeddah, Saudi Arabia. J Infect Public Health 2017; 10(4): 438-45.

[http://dx.doi.org/10.1016/j.jiph.2016.06.002] [PMID: 27422140]

[15] Al-Mohrej OA, Al-Shirian SD, Al-Otaibi SK, Tamim HM, Masuadi EM, Fakhoury HM. Is the Saudi public aware of Middle East respiratory syndrome? J Infect Public Health 2016; 9(3): 259-66. [http://dx.doi.org/10.1016/j.jiph.2015.10.003] [PMID: 26589657]

[16] Zhong BL, Luo W, Li HM, et al. Knowledge, attitudes, and practices towards COVID-19 among Chinese residents during the rapid rise period of the COVID-19 outbreak: A quick online cross-sectional survey. Int J Biol Sci 2020; 16(10): 1745-52.

[http://dx.doi.org/10.7150/ijbs.45221] [PMID: 32226294]

[17] Clements JM. Knowledge and behaviors toward COVID-19 among US residents during the early days of the pandemic: Cross-sectional online questionnaire. JMIR Public Health Surveill 2020; 6(2): e19161. [http://dx.doi.org/10.2196/19161] [PMID: 32369759]

[18] Bawazir A, Al-Mazroo E, Jradi H, Ahmed A, Badri M. MERS-CoV infection: Mind the public knowledge gap. J Infect Public Health 2018; 11(1): 89-93.

[http://dx.doi.org/10.1016/j.jiph.2017.05.003] [PMID: 28647126]

[19] Ek S. Gender differences in health information behaviour: A Finnish population-based survey. Health Promot Int 2015; 30(3): 736-45. [http://dx.doi.org/10.1093/heapro/dat063] [PMID: 23985248]

[20] Dart J, Gallois C, Yellowlees P. Community health information sources--a survey in three disparate communities. Aust Health Rev 2008; 32(1): 186-96

[http://dx.doi.org/10.1071/AH080186] [PMID: 18241163]

[21] Baseer MA, Rahman G, Yassin MA. Infection control practices in dental school: A patient perspective from Saudi Arabia. Dent Res J (Isfahan) 2013; 10(1): 25-30. [PMID: 23878560]

[22] Kamate SK, Sharma S, Thakar S, et al. Assessing knowledge, attitudes and practices of dental practitioners regarding the COVID-19 pandemic: A multinational study. Dent Med Probl 2020; 57(1): 11-7. [http://dx.doi.org/10.17219/dmp/119743] [PMID: 32307930]

[23] Khader Y, Al Nsour M, Al-Batayneh OB, et al. Dentists' awareness, erception, and attitude regarding COVID-19 and infection control: cross-sectional study among Jordanian dentists. JMIR Public Health Surveill 2020; 6(2): e18798.

[http://dx.doi.org/10.2196/18798] [PMID: 32250959]

[24] Zhang M, Zhou M, Tang F, et al. Knowledge, attitude, and practice regarding COVID-19 among healthcare workers in Henan, China. J Hosp Infect 2020; 105(2): 183-7.

[http://dx.doi.org/10.1016/j.jhin.2020.04.012] [PMID: 32278701]

(C) 2020 Mona Rajeh.

This is an open access article distributed under the terms of the Creative Commons Attribution 4.0 International Public License (CC-BY 4.0), a copy of which is available at: https://creativecommons.org/licenses/by/4.0/legalcode. This license permits unrestricted use, distribution, and reproduction in any medium, provided the original author and source are credited. 